\title{
Poverty, Voracity, and Growth
}

\author{
Holger Strulik* \\ Leibniz Universität Hannover, Discussion Paper No. 473 \\ ISSN 0949-9962
}

May 2011.

\begin{abstract}
This article investigates economic performance when enforceable property rights are missing and basic needs matter for consumption. It suggests a new view of the so-called voracity effect according to which windfall gains in productivity induce behavior that leads to lower economic growth. Taking into account that the rate of intertemporal substitution in consumption depends on the level of consumption, it is shown that "voracious behavior" is situation-specific. It occurs when an economy is in decline and sufficiently close to stagnation.
\end{abstract}

Keywords: economic growth, property rights, common pool resources, voracity, fractionalization.

JEL: O11, O13, D74, P48.

\footnotetext{
* University of Hannover, Department of Economics, Koenigsworther Platz 1, 30167 Hannover, Germany, email: strulik@vwl.uni-hannover.de. I would like to thank Karl Dietrich, Carl-Johan Dalgaard, and Pietro Peretto for useful comments.
} 


\section{INTRODUCTION}

A large empirical literature documents that economic performance suffers when institutions are weak and property rights are poorly protected. How the competition of powerful, output appropriating groups feeds back to economic growth was theoretically analyzed in a popular and influential article by Lane and Tornell (1996). They proposed to investigate appropriation behavior as a common pool resource game taking place within the framework of an $A k$ growth model. By now their model has been developed further in various directions and entered economic textbooks. ${ }^{1}$

One aspect that is emphasized by Lane and Tornell and the related literature is the so called voracity effect. Voracity means that the appropriating agents "overreact" to a positive productivity shock (or terms of trade improvement) such that the triggered increase in the speed of appropriation exceeds the gain in productivity. As a consequence growth declines after an event that would have led to higher growth under "normal" circumstances, i.e. if property rights were protected. Although thus defined voracious behavior is probably not the most natural reaction to economic shocks, Lane and Tornell have shown that voracity is indeed an observable phenomenon in the recent history of several developing countries.

Unfortunately, the modeling of the voracity effect - as it has been established in the literature so far - entails undesirable and counter-intuitive "side-effects". ${ }^{2}$ For example, the model predicts that countries of high productivity (where productivity exceeds time preference, $A>n \rho$ in the notation used below) shrink at a constant rate, whereas otherwise identical countries of low productivity (where $A<n \rho$ ) grow at a positive rate. In fact, for countries of low productivity, voracity should be a desirable feature according to the so far available theory. If voracity occurs, it turns a previously negative rate of economic growth positive.

Besides these qualitative imperfections the so far available theory entails also a quantitative problem. It needs necessarily (not sufficiently) an elasticity of intertemporal substitution in consumption larger than one for voracity to exist. While the empirical literature does not always agree with Hall (1988) that $\sigma$ is close zero, it is probably fair to say that there is consensus between quantitative macro- and empirical microeconomists that the elasticity of

\footnotetext{
${ }^{1}$ For empirical literature on property rights and growth see, for example, Acemoglu et al., 2001, Easterly and Levine, 2003, and Rodrik et al. (2004). A partial list of further developments of Lane and Tornell's approach includes Tornell and Lane (1999), Lindner and Strulik (2004, 2008), Strulik (2008b), Mino (2006), and Long and Sorger (2006). A detailed textbook treatment can be found in Drazen (2000).

${ }^{2}$ See Caselli (2006) for a similar assessment.
} 
intertemporal substitution is rarely larger than one. ${ }^{3}$ In addition, several studies have shown that $\sigma$ is particularly low for poor individuals and increasing in wealth and consumption. ${ }^{4}$

The theory has been further developed by Tornell and Lane (1999) to a two-sector setup consisting of a formal sector of high productivity and unprotected property rights and an informal sector of low productivity and protected property rights. In principle, the two-sector setup opens the possibility to extract more than current consumption from the high productivity sector and "invest" excess-extraction in the informal sector. It has been shown, however, that not investing in the informal sector is a stable, pareto-superior Nash equilibrium under the mild condition of an elasticity of intertemporal substitution in consumption smaller than unity (Strulik, 2011). Given Tornell and Lane's assumpion that initially there were no resources allocated in the informal sector, it seems plausible to conclude that the actually assumed equilibrium is the pareto-superior one. In this case the two-sector model collapses to the simple one-sector model, which is re-examined and extended in the present paper.

Specifically, the present paper re-investigates the Lane and Tornell one-sector setup assuming - in line with the empirical evidence - that the elasticity of intertemporal substitution in consumption of individuals and households is less than (or at the extreme equal to) one and that it is increasing in the level of consumption. This comparatively small refinement of the original model leads to quite drastic modifications of results and, in fact, towards a comprehensive re-assessment of the voracity effect.

In contrast to the earlier literature it will be shown that competing groups are, ceteris paribus, more likely to appropriate "too much", i.e. to generate the voracity effect, if they are living in an economy in decline, if they discount the future heavily (for example, because they are living in a high mortality environment), if aggregate productivity is low anyway, and if the society is largely fractionalized in many competing groups.

Whereas the so far available view of voracity could be interpreted as personality-specific behavior, occurring for preferences with high enough $\sigma$, the new view suggests to consider voracity as situation-specific. Individuals with the same preferences behave normally, i.e. nonvoraciously, when their income is sufficiently high, when they are populating an economy that is sufficiently productive, and when society is sufficiently little fractionalized. In that case the

\footnotetext{
${ }^{3}$ See, for example, Lucas (1990), Campbell and Mankiw (1989), and Patterson and Peseran (1992).

${ }^{4}$ Attansio and Browning (1995), Ogaki et. al (1996), Atkeson and Ogaki (1997), and Guvenen (2006).
} 
economy may even manage to grow at a positive rate. Growth, however, will in any case be lower than it could be if property rights were secure.

In order to derive these results conveniently and to provide a detailed intuition for the economic mechanism driving the voracity effect the paper is organized as follows. Section 2 sets up the problem and discusses the Euler equation that results from the consumption maximization problem of powerful groups. Section 3 solves for optimal consumption strategies in case of logutility and discusses conditions for long-run growth. Section 4 derives and explains the voracity effect. The model displays also an interesting non-monotonous effect of social fractionalization on economic growth which is derived and discussed in Section 5. Section 6 demonstrates robustness of results when utility assumes the general Stone-Geary form. Section 7 concludes.

\section{The Problem}

Consider a society consisting of $n$ groups of a measure [0,1] of individuals. A group is defined by the fact that its members cooperate with each other and compete with members of other groups. Property rights are not defined or not enforceable so that the aggregate capital stock $k$ is considered as a common pool resource. Output is produced via a linear $A k$ production technology. With missing property rights, consumption of a member of group $i, i=1, \ldots, n$, denoted by $c_{i}$, equals his or her appropriation of output. Groups are symmetric and follow a Markov strategy, $c_{i}(k)$. Let $\tilde{A}$ denote capital productivity, $\delta$ the rate of depreciation, and $A=\tilde{A}-\delta$ capital productivity net of depreciation. Thus, leftovers of output after appropriation - if there are any - define investment and the capital stock evolves according to (1).

$$
\dot{k}=A k-\sum_{j=1}^{n} c_{j}
$$

The objective of each group is to maximize for its representative member the present value of utility derived from consumption:

$$
\max _{c_{i}} \int_{0}^{\infty} u\left(c_{i}-\bar{c}\right) \mathrm{e}^{-\rho t} \mathrm{~d} t, \quad c_{i}>0 .
$$

The instantaneous utility function has the usual iso-elastic form $u(x)=\frac{\sigma}{\sigma-1} x^{\frac{\sigma-1}{\sigma}}$ for $\sigma<1$ and $u(x)=\log (x)$ for $\sigma=1 ; \rho$ denotes the time preference rate. Note that the objective is to maximize utility of an individual and not utility of a group. This approach avoids to discuss what exactly utility of a group is and it allows for a quantitative assessment since estimates 
for the parameters values of the utility function of individuals are available from the empirical literature. As mentioned in the introduction, empirical research substantiates that $\sigma$ is smaller than unity. The border case of log-utility is included because it is analytically more convenient and easier intuitively accessible.

The main feature of this so called Stone-Geary utility function, which will be crucial for the working of the model, is the parameter $\bar{c}, \bar{c} \geq 0$. In the literature $\bar{c}$ is frequently addressed as subsistence consumption although this label is in fact misleading. ${ }^{5}$ The actual function of the parameter $\bar{c}$ is to control for the empirical phenomenon that the elasticity of intertemporal substitution is increasing in income (or, strictly speaking, in the level of consumption). In order to avoid a bulky expression, I address $\bar{c}$ as "basic needs" which should be read as a shortcut for "the level of consumption at which individuals stop substituting consumption across time". Basic needs are allowed to exceed subsistence needs, i.e. consumption needed to guarantee survival of the individual. Basic needs could, for example, include expenditure for festivities, television sets, and cigarettes. With respect to the present paper the study of Atkeson and Ogaki (1996) is particular interesting since it supports the view that the curvature parameter $\sigma$ is indeed invariant over time and across countries once $\bar{c}$ is properly controlled for.

The actual elasticity of substitution in consumption $\sigma_{A}$ is, as usual, calculated from the definition $1 / \sigma_{A}=-u^{\prime \prime} / u^{\prime} \cdot c_{i}$, which provides, given the above utility function,

$$
\sigma_{A}=\sigma \cdot\left(1-\frac{\bar{c}}{c_{i}}\right)
$$

For the special case of $\bar{c}=0$, the actual elasticity is (counterfactually) constant and equals the curvature parameter $\sigma$. For $\bar{c}>0$, the actual elasticity is rising with the level of consumption and eventually approaching $\sigma$. Because individuals are more willing to substitute consumption as they become richer, i.e. to forego current satisfaction in favor for higher future gains (returns on investment), a positive $\bar{c}$ implies that the savings rate is increasing with income (see Steger, 2000, Strulik, 2010). The $\bar{c}$-modeling can also be conceptualized as a shortcut for the fact that people become more patient as they get richter (Strulik, 2009). Using Indian data Atkeson and Ogaki (1996) estimate that $\sigma_{A}$ is about 0.5 for the poorest households and 0.8 for the richest.

Since the utility function is not defined if consumption falls below $\bar{c}$, we have required additionally in (2) that $c_{i}(t)>0$ for all $t$. This assumption ensures that, if $c_{i}>\bar{c}$ cannot be realized,

${ }^{5}$ See Kraay and Radatz (2007) for a failed attempt to calibrate $\bar{c}$ as subsistence needs. See Dalgaard and Strulik (2010) for an approach to insert real subsistence needs into macroeconomics. 
a corner solution exists at which groups follow a conservative consumption strategy such that $c_{i}=A k / n, i=1, \ldots n$. A more aggressive consumption strategy at the corner, implying a more shortsighted exploitation of resources, is of course also conceivable. Non-conservative behavior would create collapse: individuals live off the capital stock until it is gone. Since the paper focusses mainly on the interior solution, the assumption for the strategy at the corner is not decisive. Requiring strictly positive consumption at all times allows us to avoid talking about non-existence and collapse. ${ }^{6}$

From the first order conditions for problem (1)-(2), after applying symmetry $\left(c_{i}=c\right.$ for all $i=1, \ldots, n)$, we find that the optimal (interior) consumption strategy $c(k)$ fulfils the Euler equation (4).

$$
A-(n-1) \cdot c^{\prime}(k)=\rho+\frac{1}{\sigma_{A}} \cdot \frac{\dot{c}}{c} .
$$

This result is in detail derived in the Appendix. The interpretation of the Euler equation follows the same intuition as in standard economic theory. It says that groups choose consumption for their representative member such that the rate of return on foregone consumption (investment) on the left hand side equals the rate of return on consumption on the right hand side. In calculating the net rate of return on investment under unprotected property rights the groups anticipate that if they invest more the other groups consume more. One unit of forgone consumption today increases gross output by $A$ and - taken for itself - this would increase the capital stock by $\dot{k}=A$. But an investing group also takes into account that the other $n-1$ groups respond to increasing capital and thus output by consuming more. Specifically, consumption per group rises by $c^{\prime}(k)$. Taken the higher appropriation of the other groups into account, an investing group faces a net return - output available for its own consumption - of $A-(n-1) c^{\prime}(k)$.

On the right hand side of (4), the rate of return on consumption (on consuming now rather than "next period") consists as usual of the rate of pure time preference plus the rate of the decrease of marginal utility from consumption caused by growing consumption. A high rate of consumption growth $\dot{c} / c$ implies an uneven consumption profile: consumption today is low in favor of consumption "next period". In order to let consumption grow at a higher rate, the group must be rewarded by a high return from investment because their representative member

\footnotetext{
${ }^{6}$ Integrating a permanent and sufficiently large flow of foreign aid into the model would allow to "harvest" the entire capital stock without collapse but would not change the qualitative behavior of the interior solution and the results on voracity. For an historical and economic analysis of collapsing societies, see Diamond (2005) and Brander and Taylor (1998).
} 
prefers a smooth consumption profile. The strength of the preference for consumption smoothing is measured by the elasticity of intertemporal substitution. If the preference for consumption smoothing is high, $\sigma_{A}$ is low and the return on investment must be high for consumption to grow over time. Recall that $\sigma_{A}$ is low when the level of consumption is low. This means that relatively poor individuals require a relatively high return on foregone consumption today. The interplay between $c^{\prime}(k)$ on the left hand side and $\sigma_{A}$ on the right hand side will explain the voracity effect.

\section{The Solution}

As Lane and Tornell we assume that groups solve the problem using linear consumption strategies $c(k)$. In order to develop stepwise the intuition for the voracity effect it may be helpful to consider for a moment the special case of log-utility and $\bar{c}=0$, that is $\sigma_{A}=1$. Guessing a solution of the form $c=\alpha k$ and thus $\dot{c} / c=\dot{k} / k$ the Euler equation requires that $A-(n-1) \alpha=\rho+A-n \alpha$. The solution is $\alpha=\rho$ and thus

$$
g \equiv \frac{\dot{k}}{k}=A-n \cdot c^{\prime}(k)=A-(n-1) \rho-\rho=A-n \rho .
$$

Aggregate capital and individual consumption grow at the rate of return minus the time preference rate, as observed for the standard $A k$ growth model. The only difference is that, with unprotected property rights, the rate of return, $A-(n-1) \rho$ is substantially lower than under protected property rights. The predicted growth rate is $A-n \rho$ instead of $A-\rho$. The presence of multiple noncooperative groups lowers the aggregate growth rate. Note that the cooperative (first best) solution is where all individuals act as one group $(n=1)$ and that it coincides with well-known market solution of the $A k$ model under secure property rights. Intuitively, without protected property rights, each group behaves as if it were "alone in the world", appropriating $\rho k$ when it should appropriate $\rho k / n$ to establish first-best economic development. As a consequence growth is decreasing in the number of competitive groups in society.

Next consider the case where $\sigma_{A}$ is a given constant, $\sigma_{A}=\sigma$. Guessing again a solution of the form $c=\alpha k$, the Euler equation (4) implies that the propensity to consume $c^{\prime}(k)=\alpha$ fulfils

$$
\alpha \cdot[n(1-\sigma)+\sigma]=A(1-\sigma)+\sigma \rho .
$$


Note that for $n=1$ the solution collapses again to the familiar solution of the $A k$ growth model under secure property rights, i.e. the textbook solution $c=[A(1-\sigma)+\sigma \rho] k$, see e.g. Chapter 4.1 of Barro and Sala-i-Martin (2004). Inserting (6) into (1), that is $\dot{k} / k=A-n \alpha$, provides the aggregate growth rate obtained by Lane and Tornell (1996).

$$
g=A-n \cdot c^{\prime}(k)=(A-n \rho) \cdot \frac{\sigma}{n(1-\sigma)+\sigma} .
$$

In order to check for voracity take the derivative $\partial g / \partial A=\sigma /[n(1-\sigma)+\sigma]$ and conclude that there exists no voracity for $\sigma<1$. In order to generate voracity it would be necessary to follow Lane and Tornell (1996) and give up the assumption $\sigma \leq 1$. Then, a necessary but not sufficient condition for voracity is $\sigma>n /(n-1)>1$. Inserting this requirement into (6) reveals that it entails another unwarranted implication. Since the left hand side gets negative, the right hand side has to get negative as well for consumption to be positive, implying $\sigma>A /(A-\rho)$. But a negative right hand side means that the model has no solution when property rights are respected (for $n=1$ ). Summarizing, the so far available theoretical foundation of the voracity effect requires not only that the elasticity of intertemporal substitution in consumption is larger than unity but also that it is so large that the consumption problem has no first-best solution, i.e. no solution when private property is protected. The present paper thus continues assuming that $\sigma \leq 1$.

Before we proceed with the discussion of endogenous $\sigma_{A}$, an inspection of the solution (5) - (7) is helpful to develop a first intuition about the role of the elasticity of intertemporal substitution for consumption behavior and voracity. For $\sigma=1$ we observe from (5) that $\partial g / \partial A=$ 1. Naturally, given log-utility, income and substitution effect balance each other, implying that groups do not change their appropriation behavior when productivity increases. As a consequence economic growth changes one to one with productivity.

For $\sigma<1$ we obtain the response of consumption behavior to an increase of $\sigma$ from (6).

$$
\frac{\partial c^{\prime}(k)}{\partial \sigma}=-\frac{A-n \rho}{[n(1-\sigma)+\sigma]^{2}}
$$

If productivity is sufficiently high such that the economy would grow perpetually for $\sigma \rightarrow 1$ (that is if $A-n \rho>0$ ), increasing $\sigma$ leads to a smaller consumption rate $c^{\prime}(k)$. Intuitively, when $\sigma$ rises groups are more easily substituting consumption over time and are more willingly 
accepting foregone current consumption in favor for future returns. This implies that economic growth reacts positively on an increase of $\sigma$ if the economy is capable of long-run growth.

The sad truth is that just the opposite is true when $A-n \rho<0$. In such an economy productivity is insufficient to allow for positive growth without protected property rights. It is an economy in decline. In this context, when the elasticity of substitution rises, groups are more readily willing to accept higher future losses in favor for higher consumption today.

The closing element to understand the voracity effect is to acknowledge that $\sigma_{A}$ is endogenous and in particular depending on productivity. Individuals consume more when productivity $A$ increases. Consequently the distance between consumption $c$ and basic needs $\bar{c}$ increases and thus the rate of intertemporal substitution $\sigma_{A}$ gets larger. This in turn raises further the preference for current consumption if the economy is in decline because future losses are more easily accepted for current gains when $\sigma_{A}$ rises.

Focussing for now on the log-specification of utility, we find the consumption strategy that satisfies the Euler equation (4) for endogenous $\sigma_{A}$ with the method of undetermined coefficients. As shown in the Appendix this leads to (9). ${ }^{7}$

$$
c(k)= \begin{cases}\rho k+\left(1-\frac{n \rho}{A}\right) \cdot \bar{c} & \text { for } k>\bar{k} \equiv n \bar{c} / A \\ A k / n & \text { for } k \leq \bar{k} .\end{cases}
$$

Plugging (9) into (1) and solving the differential equation for $k(0)=k_{0}>\bar{k}$ we obtain aggregate capital at time $t$.

$$
k(t)=\bar{k}+\left(k_{0}-\bar{k}\right) \mathrm{e}^{(A-n \rho) t} .
$$

Inspect (10) to verify the following result.

Proposition 1 (Growth). Without protected property the economy grows at a positive rate if and only if $A>n \rho$. Ceteris paribus growth is more likely to be observed, if an economy displays high productivity, if individuals are equipped with a low rate of time preference, and if social fractionalization is low. Not growing economies converge towards stagnation.

Intuitively, if the return on capital per group $A / n$ is so small that it falls short of the time preference rate $\rho$, the incentive to invest is so low that groups do not invest and the economy declines and eventually stagnates. With negative investment rates the economy converges towards

\footnotetext{
${ }^{7}$ Section 6 discusses the general case $\sigma \leq 1$ and verifies that all qualitative results are robust.
} 
stagnation. The textbook case of secure property is embedded for $n=1$, i.e. when there is only one group in society. This means also that there exists a non-empty set of parameter values for $(A, \rho)$ that allows for positive growth when private property is protected $(A>\rho)$ and that entails economic decline when property is unprotected $(A<n \rho)$. A back of the envelope calculation may be instructive. Suppose the real rate of return $A$ is 6 percent and that the economy would grow at a long-run rate $g$ of 2 percent if property rights were secure. In the present context this implies that $\rho$ equals 4 percent. Since $A-2 \rho=-2 \%$, the same economy declines at a rate of $2 \%$ when private property is unprotected and two groups appropriate output non-cooperatively.

\section{The Voracity Effect}

The aggregate growth rate $g \equiv \dot{k} / k$ is found by inserting (9) into (1) and dividing by $k$.

$$
g=A-n \rho-n \cdot\left(1-\frac{n \rho}{A}\right) \cdot \frac{\bar{c}}{k}=(A-\rho n) \cdot\left(1-\frac{n \bar{c}}{A k}\right)
$$

Taking the first and second derivative with respect to $A$ we get (12).

$$
\frac{\partial g}{\partial A}=1-\frac{n^{2} \rho}{A^{2}} \cdot \frac{\bar{c}}{k}, \quad \frac{\partial g^{2}}{\partial A^{2}}=\frac{2 n \rho}{A^{3}} \cdot \frac{\bar{c}}{k}>0
$$

This means that that there exists a productivity level for which the aggregate growth rate

assumes a minimum. Solving $\partial g / \partial A=0$ the minimum is found where $A=\sqrt{\rho \bar{c} / k} \cdot n$, which proves the following result.

Proposition 2 (Voracity). If productivity falls short of $A_{\text {min }}$, increasing productivity leads to lower growth.

$$
\frac{\partial g}{\partial A}<0 \quad \Leftrightarrow \quad A<A_{\min } \equiv \sqrt{\frac{\rho \bar{c}}{k}} \cdot n
$$

For $A>A_{\min }$ we observe the normal reaction, growth is increasing in productivity. Interestingly the critical threshold $A_{\min }$ is itself endogenous, which makes voracity a situation-specific affair.

Corollary 1 (Voracity). For given productivity A voracity occurs in economies, which are sufficiently poor ( $k$ is sufficiently low), in which individuals discount the future at sufficiently high rate $\rho$, in which the level of basic needs $\bar{c}$ is sufficiently high, and in which the society is split up in sufficiently many non-cooperative groups $n$. 
Figure 1: The Voracity Effect

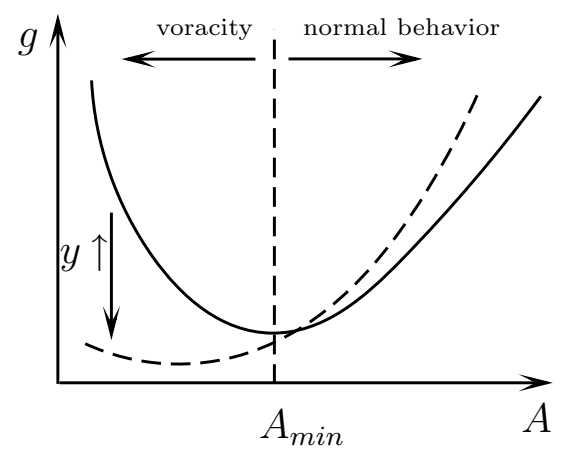

Figure 1 visualizes the result. To the left of $A_{\min }$, i.e. for low productivity, we observe voracity: a rise of productivity $A$ (or a windfall gain in the terms of trade) leads to lower growth. But because $k$ is itself endogenous, voracity is a situation-specific affair. As $k$ (or, equivalently, per capita output $y=A k)$ grows, the threshold $A_{\min }$ shifts to the left. Because voracity requires that $A<A_{\text {min }}$, this means that for any given productivity level voracity is more likely to occur in poor countries.

The fact that the threshold is endogenous provides a chance to "grow out of voracity" and a risk to "decline into voracity". It opens a door for luck in the process of development. To see this path dependence or hysteresis, it is instructive to reconsider the simple numerical example. Suppose an economy in which $\rho=0.04$ is populated by 2 groups and that $\bar{c}=1$ and $k(t)=20$. This economy needs $A>0.08$ to grow. For $A<0.06$ voracity occurs. Suppose productivity is stochastic and that the unlucky economy draws $A=0.05$. This triggers voracious behavior, which further decreases the capital stock and increases the threshold below which voracious behavior occurs. Consider, in contrast, a lucky economy drawing $A=0.1$, There voracious behavior is not an issue and the economy starts to grow. Suppose "next period's" capital stock is $k=30$, implying since the economy is richer, that an inferior draw of $A=0.05$ next period would no longer trigger voracity.

Using the definition of $\bar{k}$ from (9) the derivative in (12) can be re-stated as (13).

$$
\frac{\partial g}{\partial A}=1-\frac{n \rho}{A} \cdot \frac{\bar{k}}{k} .
$$


Since $\bar{k}<k$ for an interior solution, $A<n \rho$ is necessary for negative $\partial g / \partial A$. This observation verifies the following proposition.

Proposition 3. Voracity affects only economies in decline.

In order to understand the voracity effect we can built upon the intuition developed above. The precise response of the elasticity of intertemporal substitution in consumption to a windfall gain in productivity can be seen by inserting $c_{i}=c(k)$ from (9) into (3) which provides (14).

$$
\sigma_{A}=1-\frac{\bar{c}}{\rho k+\frac{A-n \rho}{A}} \quad \Rightarrow \quad \frac{\mathrm{d} \sigma_{A}}{\mathrm{~d} A}=\frac{\partial \sigma_{A}}{\partial c} \cdot \frac{\partial c}{\partial A}=\frac{n \rho \bar{c}^{2}}{[A(\bar{c}+\rho k)-n \rho \bar{c}]^{2}}>0 .
$$

The positive derivative in (14) establishes the amplifier needed in order to generate voracity: When $A$ rises, individuals consume more, which in turn increases their rate of intertemporal substitution. A rising rate of substitution in turn, as elaborated above, leads to even higher consumption if the economy is in decline. Facing a higher $\sigma_{A}$, individuals are more easily substituting future losses in favor for higher gains today and increase further their current consumption.

This result leads towards a refined view on the voracity effect and may indeed question whether the term "voracity" is appropriate. After all, the behavior of consuming "too much" is not a stable character trait but it is context specific. It occurs in an environment without enforceable property rights when the economy converges towards stagnation in the long run. People with the same preferences behave "normally" at higher levels of productivity and income. But "normal" behavior just means that the adverse effect of productivity does no longer exist. It does not mean "moderate" or "cooperative" because competitive groups still consume too much and invest too little vis a vis the first-best solution (see Lindner and Strulik, 2008 for the analysis of emergence and sustainability of cooperation).

The new, situation-specific view on voracity provides theoretical support for Friedman's (2005) claim that economic growth helps to sustain basic moral values. While Friedman's argument emphasizes the people's sense of getting ahead in retrospect, the current theory is forward looking. People behave "voraciously" only if they live in an environment where they do not expect the economy to grow in the future (and, additionally social fractionalization and the discount rate are high). If they expect to get ahead after a positive shock, they are predicted to behave non-voraciously. 
The model can thus explain the following scenario of unsuccessful development. At the beginning there was only one appropriating group, the colonial occupying force. Let's assume $A>\rho$ so that the economy was growing. At some moment in history the colonial power left and suddenly there were many competitive groups starting to appropriate output. Output was still relatively high during this (post-colonial) period but the society was sufficiently fractionalized so that the economy could not grow without secure property rights, i.e. $A<n \rho$. Economic growth began to decline. During the early period of decline voracious behavior was not yet an issue. Productivity gains would have made the country better off. Yet, at one point of time during the transition towards stagnation, $k$ became small enough and poverty got severe enough so that people "became voracious". Windfall gains of productivity (or of terms of trade) now worsened the problem and lead to faster convergence towards stagnation. If we imagine that this story applies roughly to many Sub-Saharan African countries and that entry into the "voracious period" occurred roughly in the 1970's, it helps to explain the combined evidence on on external shocks and growth performance compiled by Lane and Tornell $(1996,1999)$ and Rodrik (1999). ${ }^{8}$

Interestingly, Bates et al. (2007) observe that the Latin American countries after independence went through a similar phase of poor economic performance and spectacularly improving terms of trade and conclude: "Clearly, explanations for Africa's and Latin America's lost decades cannot lie with poor world market conditions." The voracity effect helps to explain how these windfalls gains actually may have contributed to the "lost decades" after independence.

Voracity, is according to the present theory identified as local phenomenon happening in "sufficiently poor" economies. But this does not mean that voracious behavior is restricted to the poorest conceivable countries with income close to subsistence level. In fact, economies can be already "sufficiently poor" for voracity when they are yet far away from stagnation and income per capita exceeds basic needs severalfolds. A numerical experiment illustrates this claim. For that purpose we consider an economy in which $n=5, \rho=0.04$, and $\bar{c}=100$. For this economy basic needs are (just) satisfied for $\bar{y} \equiv A \bar{k}=n \bar{c}=500$. We then take alternative $k$, and thus $y=A k$, and compute the productivity level $A_{\text {min }}$ below which voracity occurs (according to Proposition 2).

\footnotetext{
${ }^{8}$ In the period 1913-49 Africa grew at a rate of 1 percent and the world total at a rate of 0.9 percent, in 1950-1972 Africa grew at a rate of 2.1 percent (world total 2.9 percent), and in 1973-1992 Africa declined at a rate 0.1 percent while the world total grew at rate 1.2 percent (Bloom et al., 1998). During the period 1970-1985 Sub-Saharan Africa experienced terms of trade high above the long average (Bates et al. 2007) and growth rates declined from above 1.5 percent in 1970-1974 to -0.5 in 1974-1980 and to below -1.0 in 1980-1985 (Artadi and Sala-i-Martin, 2003).
} 
The resulting voracity threshold is depicted in Figure 2. The abscissa is scaled relative to basic needs. Close to basic needs voracity occurs when the net return on capital $A$ is below 0.11. If income exceeds basic needs by factor 2 (by factor 5 ) voracity occurs for $A$ below 0.075 (below 0.05). For a better quantitative assessment note that the economy would display positive growth for $A>0.04$ and grow at a rate of 2 percent annually for $A=0.06$ if property rights were protected. Larger $n$ or $\rho$ shifts the voracity threshold further upwards. In conclusion, for plausible parameter values the model is compatible with the observation that voracity emerges at income levels exceeding basic needs severalfolds.

Figure 2: The Voracity Threshold

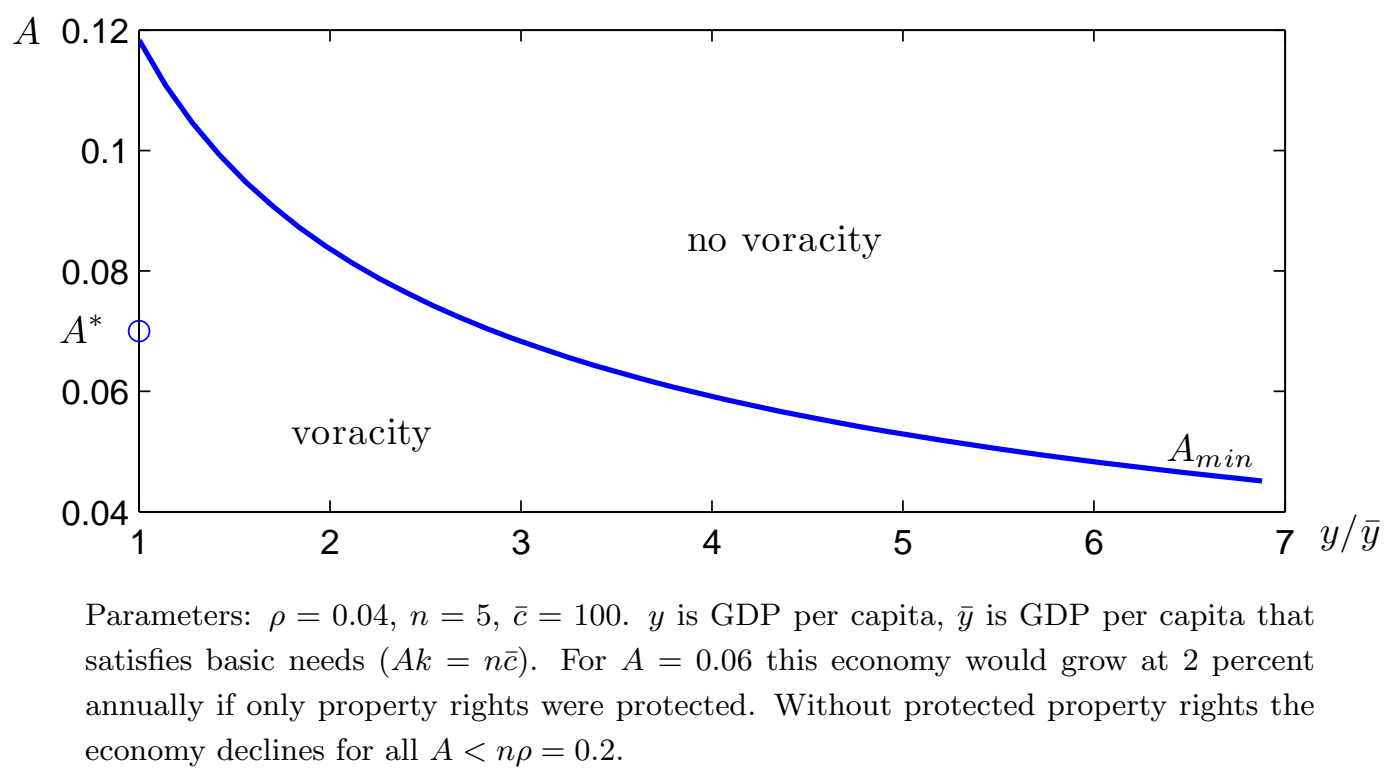

\section{Fractionalization vs. Polarization: Effects on Growth}

The model suggests also an interesting non-monotonous association between economic growth and the number of competing groups. In principle, the theory is not restricted to a particular attribute according to which groups form. But the requirement that each member of society is member of exactly one group, which follows from the underlying definition of competing groups, is reasonably well fulfilled if groups form along ethnic or religious lines. Interpreted this way, the model contributes to the literature on ethnic fractionalization and long-run growth (Easterly and Levine, 1997, Alesina et al., 2003). The association between fractionalization and growth 
can be seen by taking the derivative of $g$ with respect to the number of groups.

$$
\frac{\partial g}{\partial n}=-\frac{A-2 n \rho}{A} \cdot \frac{\bar{c}}{k}-\rho, \quad \frac{\partial^{2} g}{\partial n^{2}}=\frac{2 \rho}{A} \cdot \frac{\bar{c}}{k}>0 .
$$

Thus there exists a minimum growth rate where

$$
n=n_{\min } \equiv \frac{A}{2 \rho}\left(1+\rho \cdot \frac{k}{\bar{c}}\right)
$$

Note that $n_{\min }$ is increasing in $k$ and that at the lower boundary is $n(\bar{k})=(A / \rho+1) / 2>1$ implying that a feasible $n_{\min } \geq 2$ does always exist if the economy would grow under secure property rights (i.e. for $A>\rho$ ).

This result is interesting with respect to the polarization literature (Esteban and Ray, 1994). There it is argued that the potential for conflict is highest for polarized societies, consisting of only a few groups, so that the incentive to deviate from cooperative behavior is invertedly ushaped in fractionalization. This hypothesis is supported empirically by Keefer and Knack (2002) who find a non-linear relationship between ethnic homogeneity and the security of property rights whereby the risk of expropriation is highest for intermediate values of ethnic fractionalization. Similar results have been found by Zak and Knack (2001) with respect to trust in economic transactions and by Montalvo and Reynal-Querol (2005) with respect to ethnic polarization, potential conflict, and civil wars.

Figure 3: Fractionalization and Economic Growth

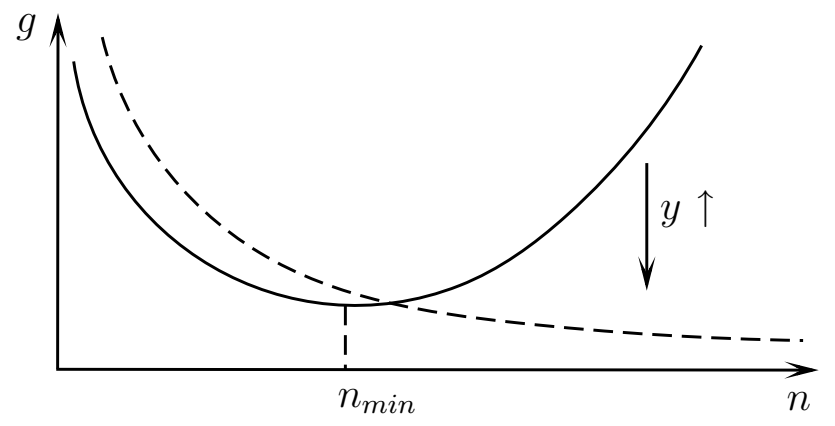

However plausible the polarization results sound, Easterly and Levine (1997) were not able to find a non-linear relationship between fractionalization and economic growth. Here we provide 
one explanation for the seemingly contradicting empirical findings. ${ }^{9}$ Inspection of (15) shows that with rising $k$ and thus per capita output $y$ the minimum at $n_{\min }$ is perpetually increasing and eventually becoming implausibly high to be actually assumed by any existing society. ${ }^{10}$ In other words, if income is sufficiently high, only the downward sloping part of the $g(n)$-curve is observable. In this case the theory supports the observed monotonously negative relationship between $n$ and growth. Figure 3 illustrates the result. This finding suggests to control for the level of aggregate poverty in the search of non-monotonous effects of fractionalization on growth.

\section{The General Case}

In order to prove robustness of the voracity results for a general class of Stone-Geary utility functions we replace (2) by (17).

$$
\max _{c_{i}} \int_{0}^{\infty} \frac{\sigma}{\sigma-1}\left(c_{i}-\bar{c}\right)^{(\sigma-1) / \sigma} \cdot e^{-\rho t} \mathrm{~d} t, \quad \sigma<1, \quad c_{i}>0
$$

In the Appendix it is shown that maximizing (17) subject to (1) is solved by the following Markovian consumption strategy $c_{i}(k)=c(k)$, for all $i=1, \ldots, n$.

$$
c(k)=\frac{\sigma}{n(1-\sigma)+\sigma} \cdot\left\{\left(1-\frac{n \rho}{A}\right) \cdot \bar{c}+\left[A \frac{(1-\sigma)}{\sigma}+\rho\right] \cdot k\right\} .
$$

For $\sigma=1$ the solution collapses to the one obtained for the simple model. The (interior) solution obtained by Tornell and Lane (1996) is also embedded, which can be seen by setting $\bar{c}=0$. Inserting the solution into the state equation, $\dot{k}=A k-n c$, provides the equilibrium growth rate (19).

$g=A-\frac{n \sigma}{n(1-\sigma)+\sigma} \cdot\left\{\left(1-\frac{n \rho}{A}\right) \cdot \frac{\bar{c}}{k}+\left[A \frac{(1-\sigma)}{\sigma}+\sigma \rho\right]\right\}=\frac{\sigma}{n(1-\sigma)+\sigma} \cdot(A-\rho n) \cdot\left(1-\frac{n \bar{c}}{A k}\right)$.

In order to discuss the voracity effect we take the derivative with respect to $A$.

$$
\begin{aligned}
\frac{\partial g}{\partial A} & =1-\frac{\sigma n}{n-\sigma(n-1)}\left(\frac{n \rho \bar{c}}{A^{2} k}\right)-\frac{(1-\sigma) n}{n-\sigma(n-1)}=\frac{\sigma}{n(1-\sigma)+\sigma}\left(1-\frac{n^{2} \rho \bar{c}}{A^{2} k}\right) \\
& =\frac{\sigma}{n(1-\sigma)+\sigma}\left(1-\frac{n \rho}{A} \cdot \frac{\bar{k}}{k}\right) .
\end{aligned}
$$

\footnotetext{
${ }^{9}$ See Lindner and Strulik (2008) for an alternative explanation.

${ }^{10}$ With respect to ethnic or ethnolinguistic fractionalization, which is the focus of most empirical studies, the information that an $n_{\text {min }}$ exists where there are, say, 1000 groups is meaningless.
} 
The second line is obtained by inserting the definition of $\bar{k}$ from (9). Inspect (18)-(20) to verify that the general case is just a scaled version of the simple case discussed with (11)- (13). The scaling factor $\sigma /[n(1-\sigma)+\sigma]$ is strictly positive for all positive $n$ and all $\sigma<1$. Thus all results from the simple case carry over to the general case.

\section{Conclusion}

This article has extended the literature on economic growth without protected property rights by taking into account that the elasticity of intertemporal substitution in consumption rises with the level of consumption. This has provided a novel and intuitively accessible explanation of the voracity effect. According to the new view voracity is conceptualized as a situation-specific affair. It occurs in economies in decline as a result of the fact that individuals after a positive shock are more easily substituting present gains for future losses of consumption.

The new view on the voracity effect offers an explanation for the poor economic performance of many post-colonial African and Latin American countries and why improving terms of trade during the "lost decades" were not helpful in getting the countries out of poverty. The theory, however, is incomplete in the sense that it cannot explain the voracity effect in growing economies. To cover these instances as well it could be worthwhile to develop the theory of voracity further in future research. 


\section{Appendix}

Derivation of the Euler Equation (4). The easiest way to solve the problem is to start with a transformation of variables. Let $\tilde{c}_{i}=c_{i}-\bar{c} \geq 0$ and $\tilde{k}=k-n \bar{c} / A \geq 0$, i.e. the deviation of consumption from subsistence level and the deviation of capital stock from subsistence capital stock. The maximization problem (1) and (2) can then be rewritten as

$$
\max _{\bar{c}_{i}} \int_{0}^{\infty} u\left(\tilde{c}_{i}\right) \mathrm{e}^{-\rho t} \mathrm{~d} t, \quad \text { s.t. } \quad \dot{\tilde{k}}=A \tilde{k}-\sum_{i=1}^{n} \tilde{c}_{j}
$$

and $\tilde{k}(0) \geq 0$. The current value Hamiltonian reads

$$
H_{i}=u\left(\tilde{c}_{i}\right)+\lambda_{i}\left(A \tilde{k}-\sum_{j=1}^{n} \tilde{c}_{j}(k)\right) .
$$

It is straightforward to check that $H_{i}$ is concave in $\left(\tilde{k}, \tilde{c}_{i}\right)$. Equilibrium strategies are found where the first order conditions

$$
\begin{array}{r}
u^{\prime}\left(\tilde{c}_{i}\right)=\tilde{c}_{i}^{-1 / \sigma}=\lambda_{i}, \\
\lambda_{i}\left[A-\sum_{j \neq i}^{n} \tilde{c}_{j}^{\prime}(k)\right]=\lambda_{i} \rho-\dot{\lambda}_{i},
\end{array}
$$

and the transversality condition $\lim _{t \rightarrow \infty} \lambda_{i}(t)\left[\tilde{k}(t)-\tilde{k}^{*}(t)\right] \mathrm{e}^{-\rho t} \geq 0$ hold for every group $i=1, \ldots, n$ and all feasible paths $\left(\tilde{k}(t), \tilde{c}_{i}(t)\right)$.

Applying symmetry, $\tilde{c}_{j}=\tilde{c}_{i}=\tilde{c}$ for all $i, j$ in (1) and (A.2), differentiating (A.1) with respect to time and substituting $\lambda_{i}$ and $\dot{\lambda}_{i}$ in (A.2) we get the equilibrium consumption strategy as defined by the following differential equation.

Re-substituting $\tilde{c}=c-\bar{c}$ provides

$$
\frac{1}{\sigma} \frac{\dot{\tilde{c}}}{\tilde{c}}=A-(n-1) \tilde{c}^{\prime}(k)-\rho
$$

$$
\frac{1}{\sigma} \cdot \frac{c}{c-\bar{c}} \cdot \frac{\dot{c}}{c}=A \rho-(n-1) \tilde{c}^{\prime}(k)-\rho .
$$

Inserting the definition $\sigma_{A}=\sigma(1-c / \bar{c})$ provides (4) in the text.

Derivation of (9). For $\sigma=1$ equation (A.3) can be written as (A.4) because $\dot{\tilde{c}}=\tilde{c}^{\prime}(\tilde{k}) \cdot \dot{\tilde{k}}$.

$$
\frac{\tilde{c}^{\prime}(\tilde{k}) \cdot \dot{\tilde{k}}}{\tilde{c}}=(A-\rho)-(n-1) \tilde{c} \quad \Leftrightarrow \quad \tilde{c}^{\prime}(\tilde{k})=\frac{(A-\rho) \tilde{c}}{A \tilde{k}-\tilde{c}} .
$$

In order to solve by the method of undetermined coefficients guess that $\tilde{c}=\alpha \tilde{k}$ and thus $\tilde{c}^{\prime}=\alpha$ and plug this into (A.4) to obtain $\alpha=\rho$ and thus $\tilde{c}=\rho \tilde{k}$.

Next, insert the solution into the equation of motion $\dot{\tilde{k}}=A \tilde{k}-n \tilde{c}$, i.e. $\dot{\tilde{k}}=A \tilde{k}-n \rho \tilde{k}$. Solve the linear, homogenous differential equation to obtain

$$
\tilde{k}(t)=\tilde{k}(0) \mathrm{e}^{(A-n \rho) t} \quad \Rightarrow \quad \tilde{c}_{i}(t)=\rho \tilde{k}(0) \mathrm{e}^{(A-n \rho) t} .
$$

Since $\tilde{k}(t) \geq 0$ for all $t$, we can check for the Malinvaud transversality condition (Sydsaeter et al., 2005, 348-349). These are fulfilled if (i)

$$
\lim _{t \rightarrow \infty} \lambda_{i}(t) \mathrm{e}^{-\rho t}\left(0-\tilde{k}^{*}(t)\right) \geq 0
$$


and (ii) there exists a $t^{\prime}$ such that $\lambda(t) \geq 0$ for all $t>t^{\prime}$. Insert $\lambda_{i}(t)$ from (A.1) and $\tilde{c}_{i}=\rho \tilde{k}$ to obtain

$$
\lim _{t \rightarrow \infty}-\frac{1}{\tilde{c}_{i}(t)} \tilde{k}(t) \mathrm{e}^{-\rho t}=\lim _{t \rightarrow \infty}\left(-\frac{1}{\rho} e^{-\rho t}\right)=0 .
$$

Thus (i) is fulfilled. Compute

$$
\lambda_{i}(t) \frac{1}{\tilde{c}_{i}(t)}=\frac{1}{\rho \tilde{k}(t)}=\frac{1}{\rho \tilde{k}_{0}} \mathrm{e}^{(n \rho-A) t} .
$$

Set $t^{\prime}=0$ to verify that $\lambda(t) \geq 0$ for all $t>t^{\prime}$ and conclude that (ii) is fulfilled. Thus, the transversality condition is fulfilled. Finally re-transformate variables $\tilde{c}_{i}=\rho \tilde{k}=\rho k-\rho n \bar{c} / A$ and $c_{i}=\tilde{c}_{i}+\bar{c}$ to arrive at $(9)$.

Derivation of (18). Insert $\dot{\tilde{c}}=\tilde{c}^{\prime}(\tilde{k}) \cdot \dot{\tilde{k}}$ and $\dot{\tilde{k}}=A \tilde{k}-n \tilde{c}$ into (A.3). After sorting terms we arrive at (A.7).

$$
\tilde{c}_{i}^{\prime}(\tilde{k})=\frac{(A-\rho) \tilde{c}_{i}}{\frac{1}{\sigma} A \tilde{k}+\left(n-1-\frac{n}{\sigma}\right) \tilde{c}_{i}} .
$$

Guessing again that $\tilde{c}_{i}=\alpha \tilde{k}$ and thus ${\tilde{c_{i}}}^{\prime}=\alpha$ and plugging this into (A.7) provides (A.8).

$$
a\left[\frac{1}{\sigma} A \tilde{k}+\left(n-1-\frac{n}{\sigma}\right) a \tilde{k}\right]=a \tilde{k}(A-\rho) .
$$

The non-trivial solution of (A.8) is

$$
\alpha=\frac{\sigma}{n(1-\sigma)+\sigma}\left[A \frac{1-\sigma}{\sigma}+\rho\right] \Leftrightarrow \tilde{c}=\frac{\sigma}{n(1-\sigma)+\sigma}\left[A \frac{1-\sigma}{\sigma}+\rho\right] \tilde{k} .
$$

The implied growth rate of $\tilde{k}=A-n \tilde{c} / k$ is

$$
\frac{\dot{\tilde{k}}}{\tilde{k}}=A-\frac{\sigma}{n(1-\sigma)+\sigma}\left[A \frac{1-\sigma}{\sigma}+\rho\right] .
$$

Since $\tilde{c}_{i}=c$ and $\tilde{k}$ grow at the same rate, the transversality condition simplifies to

$$
\left.\lim _{t \rightarrow \infty} \lambda(t)\left(0-\tilde{k}^{(} t\right)\right) e^{-\rho t}=\lim _{t \rightarrow \infty}\left(-\tilde{c}_{i}^{-1 / \sigma} \tilde{k}^{*}(t) e^{-\rho t}\right)=\lim _{t \rightarrow \infty}\left(-a \tilde{k}^{*}(t)^{-(1-\sigma) / \sigma} \mathrm{e}^{-\rho t}\right) \geq 0 .
$$

Together with (A.10) this requires that

$$
-\frac{1-\sigma}{\sigma}(A-\rho)\left[1-\frac{n \sigma}{n(1-\sigma)+\sigma} \cdot \frac{(1-\sigma)}{\sigma}\right]<0 .
$$

It is readily verified that this is always true for $\sigma<1$.

Finally re-substitute $\tilde{c}$ and $\tilde{k}$ in (A.9):

$$
c=\frac{\sigma}{n(1-\sigma)+\sigma}\left[A \frac{1-\sigma}{\sigma}+\rho\right]\left(k-\frac{\rho n \bar{c}}{A}\right)+\bar{c} .
$$

Simplifying provides (18) in the text. 


\section{References}

Acemoglu, D., Johnson, S., and Robinson, J.A., 2001, The colonial origins of comparative development: An empirical investigation, American Economic Review 91, 1369-1401.

Artadi, E.V. and Sala-i-Martin, X., 2003, The economic tragedy of the XXth century: Growth in Africa, NBER Working Paper 9865.

Alesina, A., Devleeschauwer, A., Easterly, W., Kurlat, S. and Wacziarg, R., 2003, Fractionalization, Journal of Economic Growth 8, 155-194.

Atkeson, A. and Ogaki, M., 1996, Wealth-varying elasticity of substitution: Evidence from panel data and aggregate data, Journal of Monetary Economics 38, 507-537.

Attanasio, O. and Browning, M., 1995, Consumption over the life-cycle and over the the business cycle, American Economic Review 85, 1118-1137.

Bates, R.H. and Coatsworth, J.H. and Williamson, J.G., 2007, Lost decades: Postindependence performance in Latin America and Africa, The Journal of Economic History 67, 917-943.

Bloom, D.E. and Sachs, J.D. and Collier, P. and Udry, C., 1998, Geography, demography, and economic growth in Africa, Brookings papers on economic activity 1998 (2), 207-295.

Campbell, J.Y. and Mankiw, N.G., 1989, Consumption, income, and interest rates: reinterpreting the time series evidence, in: Blanchard, O., Fischer, S. (eds.), NBER Macroeconomics Annual, MIT Press.

Caselli, F., 2006, Power struggles and the natural-resource curse, Working Paper, London School of Economics, London.

Dalgaard, C.J. and Strulik, H., 2010, The physiological foundations of the wealth of nations, University of Copenhagen Discussion Paper 10-05.

Drazen, A., 2000, Political Economy in Macroeconomics, Princeton University Press, Princeton.

Easterly, W. and Levine, R., 1997, Africa's growth tragedy: Policies and ethnic divisions, Quarterly Journal of Economics 111, 1203-1250.

Easterly, W. and Levine, R., 2003, Tropics, germs, and crops: How endowments influence economic development, Journal of Monetary Economics 50, 3-39.

Esteban, J.-M. and Ray, D., 1994, On the measurement of polarization, Econometrica 62, 819-851.

Friedman, B.M., 2005, The Moral Consequences of Economic Growth, Random House, New York.

Guvenen, F., 2006, Reconciling conflicting evidence on the elasticity of intertemporal substitution: A macroeconomic perspective, Journal of Monetary Economics 53, 1451-1472.

Hall, R.E., 1988, Intertemporal substitution in consumption, Journal of Political Economiy 96, 330-357.

Keefer, P. and Knack, S., 2002, Polarization, politics, and property rights: Links between inequality and growth, Public Choice 111, 127-54.

Kraay, A. and Raddatz, C., 2007, Poverty traps, aid, and growth,Journal of Development Economics 82, 315-347.

Lane, P.R. and Tornell, A., 1996, Power, growth, and the voracity effect, Journal of Economic Growth 1, 213-241.

Lindner, I. Strulik, H., 2004, Why not Africa? - Growth and welfare effects of secure property rights, Public Choice 120, 143-167,

Lindner, I. and Strulik, H., 2008, Social fractionalization, endogenous appropriation norms, and economic development, Economica 75, 244-258.

Long, N.V. and Sorger, G., 2006, Insecure property rights and growth: The role of appropriation costs, wealth effects, and heterogeneity, Economic Theory 28, 513-529.

Lucas, R.E., 1990, Supply-side economics: an analytical review, Oxford Economic Papers 42, 293-316. 
Mino, K., 2006, Voracity vs. scale in a growing economy without secure property rights, Economics Letters 93, 278-284.

Montalvo, J.G. and Reynal-Querol, M., 2005, Ethnic polarization, potentail conflict, and civil wars, American Economic Review 95, 796-816.

Ogaki, M., Ostry, J.D., and Reinhart, C.M., 1996, Saving behavior in low- and middle-income developing economies, IMF Staff Papers 43, 38-71.

Patterson K.D. and Peseran, B., 1992, The intertemporal elasticity of substitution in consumption in the U.S. and in the U.K., Review of Economics and Statistics 74, 573-584.

Rodrik, D., 1999, Where did all the growth go? External shocks, social conflict, and growth collapses, Journal of Economic Growth 4, 385-412.

Rodrik, D., Subramanian, A. and Trebbi, F., 2004, Institutions rule: The primacy of institutions over geography and integration in economic development, Journal of Economic Growth 9, 131-65.

Steger, T.M., 2000, Economic growth with subsistence consumption, Journal of Development Economics 62, 343-361.

Strulik, H., 2008, Social composition, Social conflict, and economic development, Economic Journal 118, 1145-1170.

Strulik, H., 2009, Patience and prosperity, University of Hannover, Discussion Paper 426, 2009.

Strulik, H., 2010, A note on economic growth with subsistence consumption, Macroeconomic Dynamics $14,763-771$.

Strulik, H., 2011, The voracity effect: comment, Discussion Paper, University of Hannover.

Sydsaeter, K., P. Hammond, A. Seierstad, and A. Strom, 2005, Further Mathematics for Economic Analysis, Pearson, Harlow.

Tornell, A., and Lane, P.R., 1999, The voracity effect, American Economic Review 89, 22-46.

Zak, P.J. and Knack, S., 2001, Trust and Growth, Economic Journal 111, 295-321. 